\title{
QUITOSANA COMO COAGULANTE NO TRATAMENTO DE ÁGUA PARA ABASTECIMENTO ${ }^{1}$
}

\author{
CHITOSAN AS COAGULANT IN WATER TREATMENT FOR SUPPLY
}

\author{
Franciele Visentini ${ }^{2}$, Cristiano Rodrigo Bohn Rhoden $^{3}$ e Liana da Silva Fernandes ${ }^{4}$
}

\section{RESUMO}

O presente trabalho teve como objetivo empregar quitosana, como coagulante, e compará-la com o sulfato de alumínio no tratamento de água, utilizando o método de tratamento convencional. A eficiência do processo foi determinada mediante a avaliação de parâmetros como cor, turbidez, odor, $\mathrm{pH}$, alcalinidade, dureza, alumínio residual e matéria orgânica. Os ensaios simulando as etapas do tratamento de água foram realizados em Jar Test, com concentrações crescentes de sulfato de alumínio $\left(12 ; 14 ; 16 ; 18 ; 20\right.$ e $\left.22 \mathrm{mg} . \mathrm{L}^{-1}\right)$ e, com quitosana $(0,5 ; 1,0 ; 1,5 ; 2,0$; 2,5 e 3,0 mg. $\left.\mathrm{L}^{-1}\right)$. Por meio dos parâmetros de cor, turbidez e menor consumo de coagulante, a concentração ideal foi de $18 \mathrm{mg} . \mathrm{L}^{-1}$ de sulfato de alumínio e $1,5 \mathrm{mg} . \mathrm{L}^{-1}$ de quitosana. Comparando-se essas duas concentrações em triplicatas no teste. Constatou-se uma redução de $95,6 \%$ na turbidez e $71 \%$ na cor com a quitosana, e de $94,1 \%$ e $86 \%$, respectivamente, com o sulfato de alumínio. O sulfato de alumínio reduziu em 42,9\% a alcalinidade e 36,8 \% a matéria orgânica, enquanto a quitosana não alterou significativamente esses parâmetros. Houve pouca alteração no pH (3,6\%), e os parâmetros de dureza, odor e alumínio residual permaneceram inalterados. Na relação custo/benefício foi demonstrado que a quitosana, apesar de eficiente, apresentou menor viabilidade econômica. Não obstante, a quitosana permanece uma alternativa de coagulante para tratamento de águas com alta turbidez pela sua eficácia, entretanto, devido ao seu custo elevado, é recomendado seu emprego como um excelente auxiliar na coagulação.

Palavras-chave: Coagulação, Biopolímero, Qualidade da água.

\section{ABSTRACT}

The present work aimed to apply the chitosan, as coagulant, and compare with aluminum sulfate, using the conventional treatment. The efficiency of the process was determinate by the evaluation of parameters such as color, turbidity, odor, $\mathrm{pH}$, alkalinity, hardness, residual aluminum, and organic matter. The tests simulating the stages of water treatment were realized in Jar Test, using increasing concentrations of aluminum sulfate (12; 14; 16; 18; 20 and $\left.22 \mathrm{mg} . \mathrm{L}^{-1}\right)$ and the concentration ranges of the chitosan $(0.5 ; 1.0 ; 1.5 ; 2.0 ; 2.5$ and $\left.3.0 \mathrm{mg} . \mathrm{L}^{-1}\right)$. Trough parameters of color, turbidity and lower coagulant consumption, the ideal concentration was $18 \mathrm{mg} . \mathrm{L}^{-1}$ of aluminum sulfate and $1.5 \mathrm{mg}$. $\mathrm{L}^{-1}$ of chitosan, comparing these two concentrations in a triplicate test. It was founded a reduction of $95.6 \%$ in turbidity and $71 \%$ in color for chitosan, and $94.1 \%$ and $86 \%$, respectively, with aluminum sulfate. The aluminum sulfate reduced in $42.9 \%$ the alkalinity and $36.8 \%$ the organic matter, while the chitosan did not significantly change these parameters. A small change in $\mathrm{pH}(3.6 \%)$ was observed, however does not affect the parameters of hardness, odor and residual aluminum. Regarding the cost/benefit relation, it was demonstrated that chitosan, although efficient, showed less economic viability. Nevertheless, chitosan remains an alternative as coagulant for water treatment with high turbidity due to its effectiveness, however, due to its high cost, its recommended the use as coagulation assistant

Keywords: Coagulation, Biopolymer, Water quality.

\footnotetext{
${ }^{1}$ Trabalho de Conclusão de Curso II.

${ }^{2}$ Acadêmica do Curso de Engenharia Química - Universidade Franciscana - UFN. E-mail: franciele.visentini@ufn.edu.br

${ }^{3}$ Colaborador - Universidade Franciscana - UFN. E-mail: cristianorbr@ufn.edu.br

${ }^{4}$ Orientadora - Universidade Franciscana - UFN. E-mail: liana@ufn.edu.br
} 


\section{INTRODUÇÃO}

É de suma importância que a água para o consumo humano seja potável, tendo em vista que, muitas vezes, a mesma necessita de um tratamento adequado e eficiente para atingir esse objetivo (BALBINOTI et al., 2018). Dentre os processos que compõem o tratamento de água convencional, destaca-se a etapa de coagulação, onde as partículas coloidais em suspenção são desestabilizadas, por meio da adição de um coagulante. Reduzindo todas as forças atrativas e, permitindo a sua agregação, facilitando sua posterior remoção por sedimentação e/ou filtração (SILVEIRA, 2017). A eficiência na etapa de coagulação é indispensável, já que interfere nos processos que a sucedem, e, portanto, está vinculada à obtenção de um produto de qualidade para o consumo humano (SILVEIRA, 2017). Visando a redução de poluentes nos processos do tratamento de água, há uma busca por alternativas tecnológicas que melhorem o desempenho da etapa de coagulação, dando ênfase à substituição de coagulantes inorgânicos por coagulantes orgânicos (SILVEIRA, 2017; RESENDE, 2018).

O coagulante inorgânico usualmente utilizado é o sulfato de alumínio $\left(\mathrm{Al}_{2}\left(\mathrm{SO}_{4}\right)_{3}\right)$, devido ao seu baixo custo e eficiência na remoção de turbidez e materiais particulados (BALBINOTI et al., 2018; RESENDE, 2018). No entanto, ao ser utilizado na água, a reação com a mesma faz com que ocorra sua dissolução, liberando íons metálicos de $\mathrm{Al}^{3+}$, que ao serem hidratados reagem e formam um precipitado de hidróxido de alumínio $\left(\mathrm{Al}(\mathrm{OH})_{3}\right)$, responsáveis por alterar as propriedades fundamentais da água (MARTINS; DE OLIVEIRA; GUARDA, 2014). Ainda a sua utilização está relacionada à produção de íons tóxicos, vinculados à ocorrência de lesões cerebrais e ao desenvolvimento de doenças, como o Alzheimer (BALBINOTI et al., 2018; RESENDE, 2018). Além dos problemas relacionados à saúde, a geração de precipitados metálicos dificulta a disposição do lodo gerado no processo dificultando sua disposição final (MARTINS; DE OLIVEIRA; GUARDA, 2014). Portanto, considerando os aspectos negativos da sua utilização, busca-se uma alternativa menos ofensiva ao meio ambiente e ao consumo humano, destacando-se a substituição por coagulantes orgânicos, como uma alternativa viável ambientalmente (RESENDE, 2018).

A utilização de coagulantes orgânicos está relacionada a aspectos positivos, como a não geração de compostos corrosivos, biodegradabilidade, pouca geração de lodo e não estão relacionados a problemas de saúde (VAZ et al., 2010; BALBINOTI et al., 2018). A quitosana é uma opção ambientalmente favorável, caracterizada por ser um biopolímero proveniente da carapaça de crustáceos, normalmente descartados industrialmente (GUIMARÃES, 2013). A quitina é um polissacarídeo encontrado em espécies vegetais e em animais marinhos (SPINELLI, 2001). A extração da quitina, ocorre pelo processo de moagem dos exoesqueletos, seguido por uma desmineralização, com solução de ácido clorídrico $(\mathrm{HCl})$, depois por uma desproteinização com solução de hidróxido de sódio $(\mathrm{NaOH})$ e segue para um processo de descoloração contendo permanganato de potássio $\left(\mathrm{KMnO}_{4}\right)$ e ácido oxálico $\left(\mathrm{C}_{2} \mathrm{H}_{2} \mathrm{O}_{4}\right)$, obtendo a quitina separando-a de outros componentes constituintes da carapaça 
(AZEVEDO et al., 2007; LACERDA, 2019). Após a obtenção, a quitina passa por um processo de desacetilação alcalina, que resulta na quitosana (AZEVEDO et al., 2007; GIRARDI, 2009).

A utilização da quitosana, como coagulante, está relacionada à eficiência na remoção de íons metálicos, turbidez e matéria orgânica, além da redução de odores, apresentando, portanto, um alto potencial para o uso no tratamento de águas para abastecimento público (GUIMARÃES, 2013). Essas características são possíveis quando a mesma se encontra em meio ácido, onde ocorrerá a protonação dos grupos amino $\left(\mathrm{NH}_{3}^{+}\right)$, fazendo com que apresente uma significativa densidade de cargas positivas. Podendo assim ser utilizada como bioadsorvente e, principalmente como coagulante (MENDES et al., 2011). Apesar das vantagens na sua utilização, a quitosana possui um elevado custo em comparação com o sulfato de alumínio (VAZ et al., 2010), já que seu valor é em torno de R\$21.020.000,00 por tonelada, enquanto o custo de produção do sulfato de alumínio de uma companhia de água do Rio Grande do Sul é em média de R \$642,00 por tonelada.

Diante disso, o presente trabalho tem como objetivo a comparação no uso dos coagulantes sulfato de alumínio e quitosana no tratamento convencional de água para abastecimento, levando em conta a capacidade e eficiência em rearranjar água contaminada, seguindo os parâmetros de potabilidade estabelecidos pela Resolução CONAMA 357/2005 que classifica os corpos de água e fixa limites para a água bruta e pela Portaria 2.914/2011 que fixa limites para a água pós tratamento, utilizada para abastecimento público. Também leva em consideração a viabilidade técnica econômica avaliada de forma comparativa no período de três meses. Neste contexto, há o desenvolvimento de uma metodologia comparativa, visando a apresentação de uma opção ambientalmente favorável e relacionada com a qualidade de vida da população, comparando-a com a atualmente empregada, considerando à aplicação em uma estação de tratamento de água (ETA) (RESENDE, 2018; HANAUER, 2019).

\section{MATERIAL E MÉTODOS}

\section{MATERIAIS}

No presente trabalho foram utilizados os coagulantes sulfato de alumínio $\left(\mathrm{Al}_{2}\left(\mathrm{SO}_{4}\right)_{3} \cdot 14 \mathrm{H}_{2} \mathrm{O}\right.$ cedida por uma companhia de água do Rio Grande do Sul) e quitosana em pó (cedida pela Universidade Franciscana - UFN).

\section{COLETA DAS AMOSTRAS DE ÁGUA}

A água bruta para os ensaios foi coletada na Estação de Tratamento de Água de Santa Maria/RS, de concessão de uma companhia de água do Rio Grande do Sul. Assim, coletaram-se três amostras simples em diferentes condições, conforme a Tabela 1, onde a amostra 1 foi utilizada para 
o pré-ensaio com o sulfato de alumínio, a amostra 2 para o pré-ensaio com a quitosana e a amostra 3 para o Jar Test com os dois coagulantes. A coleta das três amostras localiza-se na saída das adutoras da cidade e na entrada da água que passará pelo processo de tratamento. A água utilizada para abastecer a cidade é proveniente das Barragens: Saturnino de Brito, Rodolfo Costa e Silva e Vacacaí (DNOs). A água que entra na estação de tratamento consiste em uma mistura destes três afluentes.

Tabela 1 - Condições de amostragem da água bruta.

\begin{tabular}{lccc}
\hline \multirow{2}{*}{ CONDIÇÕES DA AMOSTRAGEM } & \multicolumn{3}{c}{ AMOSTRAS DE ÁGUA BRUTA } \\
\cline { 2 - 4 } & Amostra 1 & Amostra 2 & Amostra 3 \\
\hline Recipiente de coleta & Frasco plástico & Frasco plástico & Frasco plástico \\
\hline Profundidade & Superficial & Superficial & Superficial \\
Data da coleta & $06 / 09 / 2019$ & $18 / 09 / 2019$ & $27 / 09 / 2019$ \\
Horário de coleta $(\mathrm{h})$ & $13: 00$ & $8: 00$ & $13: 00$ \\
Temperatura climática $\left({ }^{\circ} \mathrm{C}\right)$ & 15 & 14 & 20 \\
Temperatura de armazenagem $\left({ }^{\circ} \mathrm{C}\right)$ & 4 & 4 & 4 \\
\hline
\end{tabular}

Fonte: Construção do autor.

\section{PREPARO DAS SOLUÇÕES COAGULANTES}

Foram preparadas duas soluções de coagulantes, onde a primeira contendo sulfato de alumínio e a segunda contendo quitosana. A amostra de sulfato de alumínio foi obtida em uma companhia de água do Rio Grande do Sul, a partir de sua densidade é possível determinar a quantidade utilizada para diluí-lo em um balão de $100 \mathrm{~mL}$, onde utilizou-se $1,52 \mathrm{~mL}$ do mesmo, obtendo uma solução contendo $1 \% \mathrm{~m} / \mathrm{v}$ de sulfato de alumínio. Para a quitosana, preparou-se uma solução contendo $1 \%$ de ácido clorídrico (HCl, Neon, 37\% P.A.) em um balão volumétrico de $100 \mathrm{~mL}$, após a diluição do ácido, adicionam-se 2 g de quitosana em pó, mantendo a solução sob agitação manual, pelo tempo de 30 minutos ou até solubilizar completamente. Desse modo, preparou-se uma solução contendo $2 \%$ de quitosana e, a partir da mesma, produziram-se soluções contendo $1 \%$ e $0,1 \%$ de quitosana, respectivamente.

\section{PRÉ-ENSAIO NO JAR TEST COM OS COAGULANTES}

O procedimento de pré-ensaio foi realizado para os dois coagulantes da mesma maneira, onde em cada copo do Jar Test marca Milan modelo JTM, foram adicionados 1L de água bruta, com concentrações crescentes de coagulante. Assim, foram utilizadas velocidades de 300 rpm por 1 minuto, 50 rpm por 4 minutos, 20 rpm por 10 minutos e 10 minutos sem agitação. Para o sulfato de alumínio, conforme a American Public Health Association (APHA), ao avaliar a matéria orgânica da água bruta, calcula-se por meio da Equação (1), a média de sulfato necessária para a água, e conforme esse valor, foram variadas as dosagens de dois em dois. 


$$
d S=M O * 5
$$

Onde dS é a concentração de sulfato de alumínio em mg.L $\mathrm{L}^{-1}$ e MO é a matéria orgânica da água bruta em mg.L. $\mathrm{L}^{-1}$ de $\mathrm{O}_{2}$.

Utilizaram-se as concentrações de sulfato de alumínio de $12 \mathrm{mg} . \mathrm{L}^{-1} ; 14 \mathrm{mg} . \mathrm{L}^{-1} ; 16 \mathrm{mg} . \mathrm{L}^{-1} ; 18 \mathrm{mg} . \mathrm{L}^{-1}$; $20 \mathrm{mg} . \mathrm{L}^{-1}$ e $22 \mathrm{mg} . \mathrm{L}^{-1}$. Para a quitosana, realizaram-se três pré-ensaios no Jar Test, onde, no primeiro foram utilizadas concentrações de $20 \mathrm{mg} . \mathrm{L}^{-1} ; 30 \mathrm{mg} . \mathrm{L}^{-1} ; 40 \mathrm{mg} . \mathrm{L}^{-1} ; 50 \mathrm{mg} . \mathrm{L}^{-1} ; 60 \mathrm{mg} . \mathrm{L}^{-1}$ e $70 \mathrm{mg} . \mathrm{L}^{-1}$; no segundo utilizou-se $3 \mathrm{mg} . \mathrm{L}^{-1} ; 6 \mathrm{mg} . \mathrm{L}^{-1} ; 9 \mathrm{mg} . \mathrm{L}^{-1} ; 12 \mathrm{mg} . \mathrm{L}^{-1} ; 15 \mathrm{mg} . \mathrm{L}^{-1}$ e $20 \mathrm{mg} . \mathrm{L}^{-1}$; no terceiro foram utilizados $0,5 \mathrm{mg} . \mathrm{L}^{-1} ; 1 \mathrm{mg} . \mathrm{L}^{-1} ; 1,5 \mathrm{mg} . \mathrm{L}^{-1} ; 2 \mathrm{mg} . \mathrm{L}^{-1} ; 2,5 \mathrm{mg} . \mathrm{L}^{-1}$ e $3 \mathrm{mg} . \mathrm{L}^{-1}$.

Avaliou-se a melhor dosagem de coagulante pelas análises de $\mathrm{pH}$ da água floculada, cor, turbidez e menor consumo do coagulante utilizado.

\section{TESTE DE JARROS}

Utilizou-se o equipamento denominado Jar Test da marca Milan modelo JTM, para simulação das etapas presentes no tratamento de água convencional. Como o equipamento possui um total de seis copos, adicionou-se $1 \mathrm{~L}$ de água bruta em cada um deles e foram realizadas triplicatas da dosagem ideal do sulfato de alumínio e da quitosana. As velocidades de rotação e o tempo utilizados foram de $300 \mathrm{rpm}$ por 1 minuto para homogeneização, para mistura rápida (coagulação) foi $50 \mathrm{rpm} / 4$ minutos, mistura lenta (floculação) foi $20 \mathrm{rpm} / 10$ minutos e sedimentação 10 minutos/sem agitação.

Após o procedimento no teste de jarros, as amostras foram filtradas, utilizando um funil e algodão.

\section{PROCEDIMENTOS ANALÍTICOS}

Os parâmetros utilizados para avaliar a qualidade da água, após o teste de jarros estão descritos na Tabela 2.

Tabela 2 - Parâmetros empregados para o monitoramento do tratamento e respectiva metodologia.

\begin{tabular}{|c|c|c|}
\hline PARÂMETRO ANALÍTICO & METODOLOGIA/EQUIPAMENTO & REFERÊNCIAS \\
\hline Cor $\left(\mathrm{mg}\right.$ PtCo.L $\left.\mathrm{L}^{-1}\right)$ & Espectrofotométrico (NOVA $60^{\mathrm{a}}$ ) & \multirow{9}{*}{ APHA (2012) } \\
\hline Turbidez (NTU) & Nefelométrico (HACH 2100Q) & \\
\hline Odor & Sensorial & \\
\hline Temperatura $\left({ }^{\circ} \mathrm{C}\right)$ & Termômetro & \\
\hline $\mathrm{pH}$ & Potenciométrico (Digimed DM-2P) & \\
\hline Alcalinidade (mg. $\mathrm{L}^{-1} \mathrm{CaCO}_{3}$ ) & Titulação volumétrica & \\
\hline Dureza $\left(\mathrm{mg} \cdot \mathrm{L}^{-1} \mathrm{CaCO}_{3}\right)$ & Titulometria por complexação & \\
\hline Matéria Orgânica $\left(\mathrm{mg} \cdot \mathrm{L}^{-1} \mathrm{O}_{2}\right)$ & Método do permanganato de potássio & \\
\hline Alumínio Residual (mg.L $\mathrm{L}^{-1} \mathrm{Al}^{3+}$ ) & Espectrofotométrico (NOVA $60^{\mathrm{a}}$ ) & \\
\hline
\end{tabular}


Para a água bruta foram analisados os parâmetros de temperatura, turbidez, cor, $\mathrm{pH}$, matéria orgânica, alcalinidade e alumínio residual. Após filtração da água bruta, mede-se a turbidez pós-filtração e cor pós-filtração. Terminado, a realização do teste de jarros, mediu-se o pH da água antes da filtração, uma vez que após a filtração foram mensurados a cor, turbidez, odor, alcalinidade, dureza, matéria orgânica e alumínio residual.

É realizada uma análise estatística para avaliar a correlação dos resultados encontrados nos pré-ensaios de cada coagulante, é utilizado o software IBM SPSS®. Utilizando o software avalia-se a correlação de Pearson da concentração de coagulante com os parâmetros analíticos encontrados.

Além dos parâmetros analíticos utilizados para o monitoramento do tratamento, também é avaliada a formação visual dos flocos.

Verificam-se os resultados, conforme a Tabela 3, se os mesmos apresentam a potabilidade da água, conforme os valores estipulados pela Resolução CONAMA 357/2005 e pela Portaria 2.914/2011. Levando em consideração que os valores da Resolução CONAMA 357/2005 são para águas doces de classe III.

Tabela 3 - Valor máximo dos parâmetros físico-químicos estipulados pela Resolução CONAMA 357/2005 e pela Portaria 2.914/2011.

\begin{tabular}{ll}
\hline \multicolumn{1}{c}{ PARÂMETROS FÍSICO-QUÍMICOS } & VALOR MÁXIMO ESIPULADO \\
\hline Cor & $15 \mathrm{mg} \mathrm{Pt}-\mathrm{Co} . \mathrm{L}^{-1}$ \\
\hline Turbidez & $5 \mathrm{NTU}$ \\
\hline Odor & Inodoro \\
\hline Temperatura & - \\
\hline $\mathrm{pH}$ & Faixa de 6,0 até 9,5 \\
\hline Alcalinidade & - \\
\hline Dureza & $500 \mathrm{mg} \cdot \mathrm{L}^{-1}$ \\
\hline Matéria Orgânica & - \\
\hline Alumínio residual & $0,2 \mathrm{mg} \cdot \mathrm{L}^{-1}$ \\
\hline
\end{tabular}

Fontes: BRASIL, 2005; BRASIL, 2011.

\section{VIABILIDADE TÉCNICA ECONÔMICA}

O estudo de viabilidade técnica econômica foi realizado através da avaliação do histórico do consumo diário e de custo, num período de três meses. Assim, os valores de produção de cada coagulante foram obtidos e de maneira comparativa, avaliado o custo de utilização de cada coagulante, conforme as concentrações de cada um deles. O custo médio do sulfato de alumínio consumido por uma companhia de água do Rio Grande do Sul é de R\$ 642,00 por tonelada, enquanto o custo da quitosana em pó comercial é em média de R\$21.020.000,00 por tonelada. 


\section{RESULTADOS E DISCUSSÃO}

\section{CARACTERIZAÇÃO DA ÁGUA BRUTA}

Foram caracterizadas três águas brutas, a amostra 1 para a realização do pré-ensaio com sulfato de alumínio, a amostra 2 para realização dos pré-ensaios com a quitosana e a amostra 3 para a realização do teste de jarros. Na Tabela 4 estão apresentados os resultados dos parâmetros analíticos encontrados.

Tabela 4 - Parâmetros analíticos das amostras de água bruta.

\begin{tabular}{|c|c|c|c|}
\hline \multirow{2}{*}{ PARÂMETROS ANALÍTICOS } & \multicolumn{3}{|c|}{ AMOSTRAS DE ÁGUA BRUTA } \\
\hline & Amostra 1 & Amostra 2 & Amostra 3 \\
\hline Temperatura $\left({ }^{\circ} \mathrm{C}\right)$ & 14,0 & 15,0 & 15,8 \\
\hline Turbidez (NTU) & 5,50 & 4,23 & 3,33 \\
\hline Cor (mg PtCo.L-1) & 18,0 & 14,5 & 13,1 \\
\hline $\mathrm{pH}$ & 7,00 & 6,84 & 6,89 \\
\hline Matéria Orgânica $\left(\mathrm{mg} \cdot \mathrm{L}^{-1} \mathrm{O}_{2}\right)$ & 2,9 & 2,7 & 2,9 \\
\hline Alcalinidade (mg. $\left.\mathrm{L}^{-1} \mathrm{CaCO}_{3}\right)$ & 20,0 & 20,0 & 21,0 \\
\hline Dureza (mg.L $\mathrm{L}^{-1} \mathrm{CaCO}_{3}$ ) & - & - & 19,0 \\
\hline Alumínio Residual (mg.L $\mathrm{L}^{-1} \mathrm{Al}^{3+}$ ) & 0,0 & - & 0,0 \\
\hline Turbidez da água pós-filtração (NTU) & 3,94 & 3,32 & 2,54 \\
\hline Cor da água pós-filtração (mg PtCo.L-1 $)$ & 15,8 & 12,2 & 11,0 \\
\hline
\end{tabular}

Fonte: Construção do autor.

Conforme a Tabela 4, constata-se uma pequena variação nos parâmetros da água bruta, que pode ser justificada devido às diferenças climáticas ocorridas dentre os dias que as caracterizações foram realizadas.

Posterior à filtração das amostras, percebe-se pouca alteração nos parâmetros de cor e turbidez, indicando que a água deve passar pelos processos de coagulação, floculação e decantação, além da filtração, com a finalidade de obter um produto de mais qualidade.

\section{PRÉ-ENSAIOS COM OS COAGULANTES}

Para o sulfato de alumínio, foram utilizadas seis diferentes concentrações, avaliando os parâmetros de $\mathrm{pH}$ antes e, após a filtração, avaliou-se a cor, turbidez, alumínio residual e dosagem econômica de coagulante. Na Tabela 5 estão demonstrados os resultados desses parâmetros. 
Tabela 5 - Parâmetros analíticos da água bruta e do pré-ensaio com sulfato de alumínio.

\begin{tabular}{|c|c|c|c|c|}
\hline \multirow{2}{*}{$\begin{array}{l}\text { CONCENTRAÇÃO } \\
\left(\mathrm{mg} . \mathrm{L}^{-1}\right)\end{array}$} & \multicolumn{4}{|c|}{ PARÂMETROS ANALÍTICOS } \\
\hline & $\begin{array}{l}\text { pH sem } \\
\text { filtração }\end{array}$ & Cor (mg PtCo.L $\left.{ }^{-1}\right)$ & Turbidez (NTU) & $\begin{array}{c}\text { Alumínio Residual } \\
\left(\mathrm{mg} \cdot \mathbf{L}^{-1} \mathbf{A l}^{3+}\right)\end{array}$ \\
\hline Água Bruta & 7,0 & 18 & 5,5 & 0,0 \\
\hline 12 & 6,75 & 8,4 & 2,16 & 0,4 \\
\hline 14 & 6,77 & 4,6 & 0,62 & 0,2 \\
\hline 16 & 6,78 & 3,4 & 0,29 & 0,1 \\
\hline 18 & 6,80 & 2,5 & 0,17 & 0,0 \\
\hline 20 & 6,60 & 2,2 & 0,11 & 0,0 \\
\hline 22 & 6,60 & 2,1 & 0,12 & 0,1 \\
\hline
\end{tabular}

Fonte: Construção do autor.

Conforme a Tabela 5, constata-se que não houve alterações significativas no $\mathrm{pH}$, apenas há uma redução do mesmo em relação ao $\mathrm{pH}$ da água bruta, esta é uma característica do sulfato de alumínio, onde ele consome a alcalinidade da água, e, portanto, essa redução (GERHARDT, 2018). Analisando a correlação de Pearson (r) entre a concentração de sulfato de alumínio e o pH, tem-se uma correlação negativa significativa $(\mathrm{r}=-0,904)$, sendo assim, conforme aumenta a concentração de alumínio, diminui o valor do $\mathrm{pH}$.

Ao aumentar a concentração de sulfato de alumínio, há uma redução nos valores de cor e turbidez, em comparação com os resultados obtidos por SPINELLI (2011). Na faixa de 10 a 20 mg.L-1 de sulfato de alumínio, observa-se uma redução nos teores de cor e turbidez ao aumentar a concentração. Porém, nos resultados obtidos por SPINELLI (2011), onde a concentração de sulfato de alumínio foi superior a $20 \mathrm{mg} . \mathrm{L}^{-1}$, há um aumento nos valores de cor e turbidez. Sendo assim, na faixa de concentração de 10 a 20 mg.L $\mathrm{L}^{-1}$ de sulfato de alumínio encontram-se os melhores resultados de cor e turbidez, já que a reação entre o coagulante e as partículas coloidais ocorreu de maneira desejada, enquanto valores abaixo ou acima dessa faixa não são eficientes para remoção de cor e turbidez, devido ao fato de não ocorrer a reação de forma efetiva entre o coagulante e as partículas coloidais. Analisando a correlação entre a concentração e as variáveis de cor e turbidez, tem-se uma correlação negativa significativa, sendo assim, na faixa de concentração avaliada quando há um aumento na concentração de sulfato de alumínio, diminuíram os teores de cor e turbidez (as correlações de Pearson (r) são, respectivamente, $\mathrm{r}=-0,973$ e $\mathrm{r}=-0,958)$.

Quando a dosagem de sulfato de alumínio é muito baixa ou muito alta, tem-se um aumento no alumínio residual. Segundo Rosalino (2011), esse alumínio residual alto em baixas concentrações, deve-se ao fato de não ter ocorrido a reação completa entre o sulfato de alumínio e as partículas coloidais. Isto se comprova, inclusive, visualmente má formação de flocos de maneira efetiva. Assim, ao ter uma concentração maior que a desejada de sulfato de alumínio, há alumínio residual pelo excesso desnecessário do mesmo (ROSALINO, 2011). 
O valor máximo de alumínio residual estipulado pela Portaria $n^{0} 2.914 / 2011$ é de 0,2 mg.L-1. Portanto, a dosagem ideal e mais econômica do sulfato de alumínio foi a de $18 \mathrm{mg} . \mathrm{L}^{-1}$, já que apresentou um baixo teor de cor e turbidez, assim como, não apresentou alumínio residual.

Para a quitosana realizaram-se testes com 15 dosagens diferentes, encontrando-se a faixa de coagulação da mesma, onde foram avaliados os parâmetros de $\mathrm{pH}$ antes da filtração, uma vez que após a filtração, mede-se a cor e a turbidez, conforme a Figura 1.

Figura 1 - Parâmetros avaliados de pH (a), cor (b) e turbidez (c) ao utilizar dosagens variadas de quitosana como coagulante.
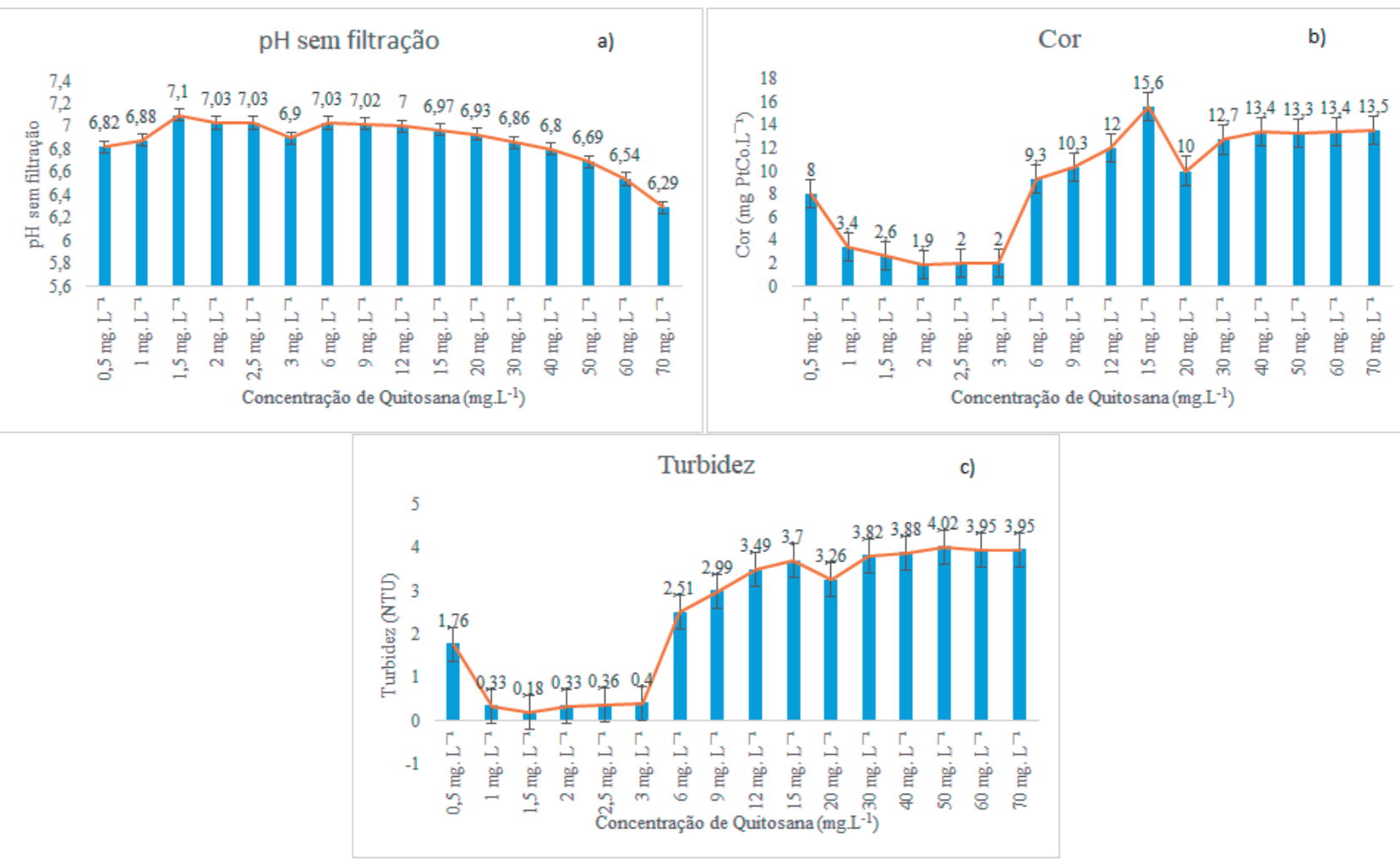

Fonte: Construção do autor.

De acordo com a Figura 1(a), observa- se que o pH não demonstrou uma variação muito grande nas dosagens de 0,5 até $12 \mathrm{mg} \cdot \mathrm{L}^{-1}$ de quitosana $(6,82$ - 7,0), porém em concentrações maiores que $12 \mathrm{mg} . \mathrm{L}^{-1}$ houve uma redução no pH $(7,0$ - 6,29). Essa redução no pH, em concentrações muito elevadas, pode ser explicada pela utilização da solução de ácido clorídrico para auxiliar para solubilizar a quitosana, o qual possui um $\mathrm{pH}$ baixo e em excesso pode alterar o $\mathrm{pH}$ da água, baixando seu valor (SPINELLI, 2001). Observou-se também, que apesar de ter pouca variação no pH na faixa de concentração de 1 a 30 mg.L $\mathrm{L}^{-1}$, seu valor excede ao valor da água bruta, esse aumento no pH pode ser explicado pela capacidade da quitosana em neutralizar a acidez da água de abastecimento, devido à presença de metais na água bruta, que ao entrar em contato com os grupos amino da quitosana, 
são precipitados na forma de hidróxidos (DE ALMEIDA et al., 2016). A análise de correlação apresentou uma correlação negativa significativa entre a concentração de quitosana e o pH (r=-0,854), entende-se, portanto, que ao ter-se um aumento na concentração, há uma redução no pH.

A Figura 1(b), mostra um valor alto de cor quando se tem um excesso de quitosana na faixa de concentração de 6 a $70 \mathrm{mg} . \mathrm{L}^{-1}$, assim como também ocorre em quantidades menores de quitosana $\left(0,5 \mathrm{mg} \cdot \mathrm{L}^{-1}\right)$. Verifica-se que a cor possui valores mais desejáveis nas concentrações de 1 até $3 \mathrm{mg} . \mathrm{L}^{-1}$ de quitosana. Conforme a Figura 1(c) quando há um excesso de quitosana, na faixa de concentração de 6 a 70 mg.L $L^{-1}$, há um aumento na turbidez. Quando em concentração baixa de 0,5 mg. $\mathrm{L}^{-1}$, há pouca remoção na turbidez. A faixa de dosagem com os valores mais desejáveis de turbidez é de 1 até $3 \mathrm{mg}$. $\mathrm{L}^{-1}$ de quitosana. A análise de correlação da concentração de quitosana com a cor e a turbidez, resultou em uma correlação positiva moderada nos dois casos (respectivamente $\mathrm{r}=0,600$ e $\mathrm{r}=0,644)$.

Conforme Spinelli (2011), o aumento na cor e na turbidez, quando há altas concentrações de quitosana, pode ser explicado pelo aumento dos grupos $-\mathrm{NH}_{3}^{+}$em solução, que ao estarem presentes no meio em excesso tendem a romper ligações entre a quitosana e as partículas coloidais, ocasionando esse aumento nos valores de cor e turbidez no meio. Assim como, ao ter uma concentração baixa como em $0,5 \mathrm{mg} . \mathrm{L}^{-1}$, a reação de maneira menos efetiva entre a quitosana e as partículas coloidais, resultando e um aumento nos teores de cor e turbidez.

$\mathrm{Na}$ concentração de $15 \mathrm{mg} . \mathrm{L}^{-1}$, observa-se um valor de cor 15,6 mg.PtCol.L $\mathrm{L}^{-1}$, superior ao valor máximo estabelecido pela Portaria $n^{\circ}$ 2.914/2011, esse valor pode ser justificado pelo excesso de coagulante, ocorrendo a quebra das ligações entre a quitosana e as partículas coloidais (SPINELLI, 2011).

Sendo assim, a faixa de dosagens de quitosana que apresentou os melhores resultados é entre 1 e $3 \mathrm{mg} . \mathrm{L}^{-1}$. Determinou-se, portanto, que a melhor dosagem de quitosana, que apresentou valores baixos de cor, turbidez e menor consumo de coagulante foi de $1,5 \mathrm{mg} . \mathrm{L}^{-1}$. Estes valores corroboram com o trabalho de Spinelli (2011), que demonstrou como sendo a melhor concentração de quitosana na faixa de $1,5 \mathrm{mg} . \mathrm{L}^{-1}$ a $2,0 \mathrm{mg} . \mathrm{L}^{-1}$, relacionados a remoção na cor e turbidez.

\section{ENSAIOS NO JAR TEST COM SULFATO DE ALUMÍNIO E QUITOSANA}

No Jar Test, conforme a Figura 2, colocou-se em cada um dos três primeiros copos 18 mg.L-1 do coagulante sulfato de alumínio, enquanto em cada um dos três últimos $1,5 \mathrm{mg} . \mathrm{L}^{-1}$ de quitosana. 
Figura 2 - Jar Test com o sulfato de alumínio e quitosana.

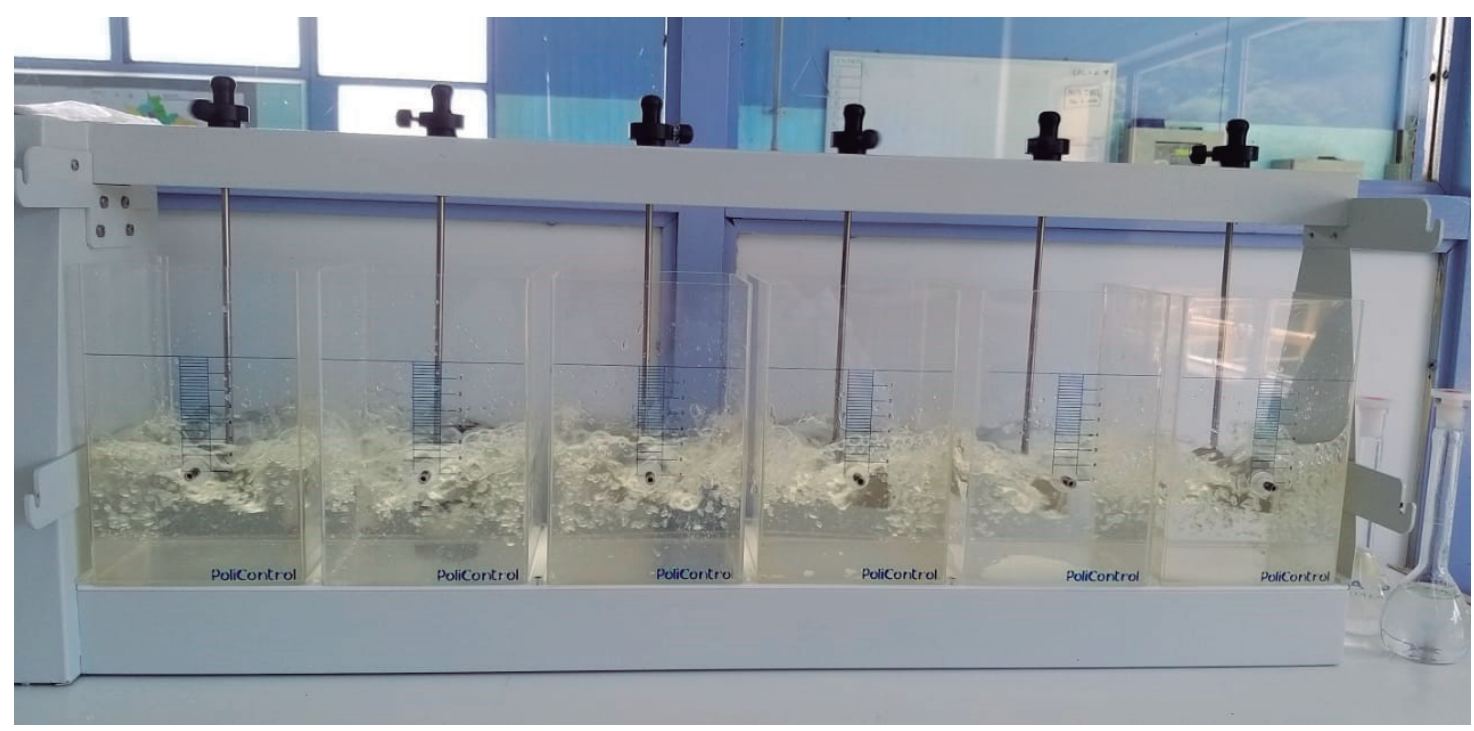

Fonte: Registro do autor.

Avaliou-se o pH dos jarros após os testes, sem filtrar os conteúdos, após a filtração avaliou-se os parâmetros de cor, turbidez, alcalinidade, matéria orgânica, alumínio residual e dureza, conforme a Tabela 6.

Tabela 6 - Resultado dos parâmetros analíticos da água bruta e do Jar Test com sulfato de alumínio e quitosana.

\begin{tabular}{|c|c|c|c|c|c|c|c|}
\hline \multirow{3}{*}{$\begin{array}{l}\text { PARÂMETROS } \\
\text { ANALÍTICOS }\end{array}$} & \multirow{3}{*}{$\begin{array}{l}\text { Água } \\
\text { Bruta }\end{array}$} & \multicolumn{6}{|c|}{ COAGULANTES } \\
\hline & & \multicolumn{3}{|c|}{ Sulfato de alumínio (18 $\left.\mathrm{mg} \mathrm{L}^{-1}\right)$} & \multicolumn{3}{|c|}{ Quitosana (1,5 $\left.\mathrm{mg} \mathrm{L}^{-1}\right)$} \\
\hline & & Copo 1 & Copo 2 & Copo 3 & Copo 4 & Copo 5 & Copo 6 \\
\hline pH antes da filtração & 6,89 & 6,76 & 6,83 & 6,84 & 7,03 & 7,17 & 7,16 \\
\hline Cor (mg PtCo.L-1) & 13,1 & 1,8 & 2,0 & 1,7 & 3,7 & 3,8 & 3,9 \\
\hline Turbidez (NTU) & 3,33 & 0,21 & 0,21 & 0,17 & 0,15 & 0,14 & 0,15 \\
\hline Alcalinidade (mg. $\left.\mathrm{L}^{-1} \mathrm{CaCO}_{3}\right)$ & 21 & 12 & 12 & 12 & 19 & 19 & 19 \\
\hline Matéria Orgânica (mg.L ${ }^{-1} \mathrm{O}_{2}$ ) & 2,9 & 1,9 & 1,8 & 1,8 & 2,5 & 2,2 & 2,5 \\
\hline Alumínio Residual (mg. $\mathrm{L}^{-1} \mathrm{Al}^{3+}$ ) & 0,0 & 0,0 & 0,0 & 0,0 & 0,0 & 0,0 & 0,0 \\
\hline Dureza $\left(\mathrm{mg} \cdot \mathrm{L}^{-1} \mathrm{CaCO}_{3}\right)$ & 19 & 18 & 18 & 18 & 19 & 19 & 19 \\
\hline Odor & & \multicolumn{6}{|c|}{ Inodoro } \\
\hline
\end{tabular}

Fonte: Construção do autor.

Os resultados de $\mathrm{pH}$ antes da filtração para o sulfato de alumínio, mostraram-se próximos à água bruta, enquanto a quitosana teve resultados com uma média de 3,6\% de acréscimo no valor da água bruta. Esses valores são devidos as características de cada coagulante, onde o sulfato de alumínio consome a alcalinidade do meio, obtendo um $\mathrm{pH}$ um pouco mais baixo, e a quitosana não possui a característica de consumir alcalinidade, mas de neutralização do meio ao entrar em contato com metais, elevando, portanto os valores de pH entre 7,03 e 7,16 (DE ALMEIDA et al, 2016; GERHARDT, 2018).

Verifica-se que para o parâmetro de cor, o sulfato de alumínio teve uma eficiência maior na remoção, com uma média de $86 \%$ de remoção de cor $(86,26 \%$ no copo $1 ; 84,75 \%$ no copo $2 ; 87,02 \%$ no copo 3). A quitosana apresentou uma eficiência na média de $71 \%$ na remoção da cor $(71,76 \%$ no 
copo 4; 70,99\% no copo 5; 70,23\% no copo 6). Para Spinelli (2011), o sulfato de alumínio apresentou uma redução de 95\% de cor, enquanto a quitosana obteve uma redução de 91,7\%.

Para a turbidez, o coagulante que obteve a melhor eficiência em remoção foi a quitosana com uma média de $95,6 \%$ (95,49\% no copo $4 ; 95,80 \%$ no copo $5 ; 95,49 \%$ no copo 6$)$, enquanto o sulfato de alumínio teve uma redução em torno de $94,1 \%$ na turbidez (93,69\% no copo 1; 93,69\% no copo 2; $94,89 \%$ no copo 3). Contrapondo o estudo de Spinelli (2011), onde a quitosana (94,6\%) obteve valores inferiores de remoção na turbidez comparada ao sulfato de alumínio $(97,1 \%)$.

No parâmetro de alcalinidade, o sulfato de alumínio demonstrou uma efetividade em torno de 42,9\%, enquanto a quitosana não apresentou grande alteração nesse valor, reduzindo apenas 9,52\%. Demostrando a capacidade do sulfato de alumínio em consumir a alcalinidade do meio. Da mesma forma ocorrendo com a matéria orgânica, onde, o sulfato de alumínio reduziu uma média de 36,8\% e a quitosana teve pouca alteração em comparação com o valor da água bruta, reduzindo em média 17,24\%.

Para os parâmetros de alumínio residual e dureza observa-se que não há uma diferença significativa entre o sulfato de alumínio e a quitosana.

Constatou-se a diferença na formação dos flocos, enquanto o sulfato de alumínio forma flocos grandes e densos, a quitosana formou filamentos com a característica de serem coloidais e aderentes, considerando-se que, em alguns casos, fixaram-se nas pás do equipamento. Percebeu-se também, que após o tempo de decantação, os flocos do sulfato de alumínio sedimentam completamente, enquanto os filamentos da quitosana ficaram em grande parte suspensos na água e apresentando sedimentação apenas parcial.

\section{ANÁLISE ECONÔMICA}

O valor do sulfato de alumínio utilizado é em média R\$ 642,00 por tonelada, enquanto o valor da quitosana produzida industrialmente é em média R\$21.020.000,00 por tonelada. Por meio dos testes de jarros, em média para cada litro de água seriam gastos R $\$ 0,000011556$ de sulfato de alumínio, enquanto para a quitosana seriam gastos $\mathrm{R} \$ 0,03153$.

Sabendo-se da vazão média em torno de 1000 L.s ${ }^{-1}$ em uma estação de tratamento de água, seriam gastos com os coagulantes $\mathrm{R} \$ 0,011556$ de sulfato de alumínio e $\mathrm{R} \$ 31,53$ de quitosana, a cada segundo. Durante o período de um dia o valor de sulfato de alumínio utilizado seria de R\$998,44 e o de quitosana seria $\mathrm{R} \$ 2.724 .192,00$.

Avaliando a utilização dos coagulantes no período de três meses, tem-se um custo com a coagulação de R \$29.953,20 para o sulfato de alumínio e de R \$ 81.752.760,00 para a quitosana. Leva-se em consideração que nesse período seriam gastos por uma companhia de água do Rio Grande do Sul em torno de R \$ 957.612,00 com o tratamento do lodo contendo sulfato de alumínio, resultando num total de R\$ 987.565,20 para a utilização do sulfato de alumínio na coagulação seguido pelo tratamento do seu resíduo. 
Conclui-se que a quitosana é uma opção ambientalmente favorável para ser utilizada como coagulante, porém, na água bruta na qual os testes foram realizados, o sulfato de alumínio conseguiu potabilizar a água de modo mais eficiente. Sua utilização poderia ser mais eficiente se fosse utilizada como adjuvante de coagulação.

\section{CONCLUSÃO}

Com os pré-ensaios realizados foi possível determinar as melhores concentrações de sulfato de alumínio e quitosana, respectivamente, $18 \mathrm{mg} . \mathrm{L}^{-1} \mathrm{e} 1,5 \mathrm{mg} . \mathrm{L}^{-1}$, pois apresentaram os melhores resultados para a remoção de cor e turbidez da água, além de um menor consumo. Para o sulfato de alumínio analisou-se o alumínio residual, onde na melhor concentração não foi identificada a presença deste na água.

Avaliando os resultados dos dois coagulantes nas mesmas condições, observa-se que a quitosana é uma opção a ser utilizada em águas de alta turbidez, já que apresentou resultados melhores que o sulfato de alumínio na remoção da mesma, além de estar condizente com a Portaria $n^{\circ}$ 2.914/2011 que estabelece o valor máximo de 5 NTU. Para a remoção de cor, apesar de não ter apresentando a mesma eficiência comparada ao sulfato de alumínio, os valores observados estão de acordo com Portaria 2.914/2011 que estabelece um valor máximo de 15 mg.PtCol.L ${ }^{-1}$. Para águas com concentração de matéria orgânica mais elevadas serão necessários testes adicionais e adequações considerando que a quitosana demonstrou resultados insatisfatórios na redução desse parâmetro.

No parâmetro de alcalinidade, constatou-se que a quitosana não altera significativamente a alcalinidade da água, característica associada ao emprego do sulfato de alumínio. Consequentemente, em águas com baixa alcalinidade o tratamento com sulfato de alumínio necessita de complementação com um agente alcalinizante, enquanto a quitosana não teria esta necessidade. Em águas com alcalinidade desejada, a quitosana seria uma alternativa de uso comparada ao sulfato de alumínio.

Nos parâmetros de dureza, odor e alumínio residual ambos, sulfato de alumínio e quitosana, apresentaram os mesmos resultados, todos condizentes com a Resolução CONAMA 357/2005 e com a Portaria 2.914/2011.

Além dos parâmetros legais, ao se avaliar a formação dos flocos, observou-se uma formação de flocos mais efetiva por parte do sulfato de alumínio: grandes flocos e sedimentação completa. Com a quitosana ocorreu a formação de filamentos e uma decantação não uniforme com parte destes aderindo aos floculadores e a formação de um filme nos filtros, impedindo o funcionamento ótimo do equipamento.

Não obstante, conclui-se com a análise econômica que, ao utilizar a quitosana como coagulante, apesar de não necessitar de um tratamento de lodo tão vigoroso quanto o sulfato de alumínio, seu custo é superior. Portanto, sua utilização como coagulante é de viabilidade preponderante ambiental quando comparada ao sulfato de alumínio. 


\section{REFERÊNCIAS}

AMERICAN PUBLIC HEALTH ASSOCIATION (APHA). Standard Methods to the Examination of Water and Waste. 20 ed. Washington: APHA, 1999. 630 p.

AZEVEDO, V. V. C. et al. Quitina e Quitosana: Aplicação Como Biomateriais. Revista Eletrônica de Materiais e Processos, v. 2, n. 3, p. 27-34, 2007.

BALBINOTI, J. R. et al. Uso de Sementes de Moringa oleifera Como Agente Coagulante Para o Tratamento de Água. Revista Brasileira de Geografia Física, v. 11, n. 05, p. 1748-1760, 2018.

BRASIL. Ministério da Saúde (MS). Gabinete do Ministro. Portaria no 2.914, de 12 de dezembro de 2011. Dispõe sobre os procedimentos de controle e de vigilância da qualidade da água para consumo humano e deu padrão de potabilidade. Diário Oficial da União, p. 39-46, 24 dez. 2011.

BRASIL. Ministério do Meio Ambiente (MMA). Conselho Nacional do Meio Ambiente - CONAMA. Resolução $n^{0} 357$, de 17/03/2005. Dispõe sobre a classificação dos corpos de água e diretrizes ambientais para o seu enquadramento, bem como estabelece as condições e padrões de lançamento de efluentes, e dá outras providências. Diário Oficial da União, p. 58-63, 18 de mar. 2005.

DE ALMEIDA, E. E. O. S. et al. Síntese e Caracterização da Membrana Quitosna/Perlita. In: CONGRESSO NACIONAL DE PESQUISA E ENSINO EM CIÊNCIAS, 1., 2016, Campina Grande. Anais... Campina Grande: UEPB, 2016. 8 p.

HANAUER, T. V. et al. Aplicação de Coagulantes Químico e Orgânico para o Tratamento de Efluente de Abatedouro Avícola. Revista Brasileira de Energias Renováveis, v. 8, n. 2, p. 480-493, 2019.

GERHARDT, C. M. Uma Alternativa de Substituição ao Sulfato de Alumínio no Tratamento de Água Potável. 2018. 79 f. Trabalho de Conclusão de Curso (Graduação em Química Industrial) Instituto de Química, Universidade Federal do Rio Grande do Sul, 2018.

GIRARDI, F. Tratamento de Vinhaça Utilizando Coagulantes Naturais. 2009. 98 f. Dissertação de Mestrado (Programa de Pós-Graduação em Engenharia Química), Universidade Estadual de Maringá, Maringá, 2009. 
GUimarÃes, P. S. Tratamento de Águas Residuárias Oriundas da Purificação do Biodiesel por Coagulação Empregando Sulfato de Alumínio e Quitosana: Avaliação Preliminar. 2013. 78

f. Dissertação (Mestrado em Tecnologia Ambiental e Recursos Hídricos) - Faculdade de Tecnologia, Universidade de Brasília. Brasília, 2013.

LACERDA, B. A. C. F. Otimização e Padronização de Processos Para Obtenção de Quitosana Purificada Para Uso Farmacêutico e Alimentício. 2019. 109 f. Dissertação de Mestrado (Programa de Pós-Graduação em Fármaco e Medicamentos) - Faculdade de Ciências Farmacêuticas, Universidade de São Paulo, São Paulo, 2019.

MARTINS, A. A.; DE OliveIRA, R. M. S.; GUARDA, E. A. Potencial de Uso de Compostos Orgânicos Como, Coagulantes, Floculantes e Adsorventes no Tratamento de Água e Efluentes. X Fórum Ambiental da Alta Paulista: Saúde, Saneamento e Meio Ambiente, v. 10, n. 12, p. 168-183, 2014.

MENDES, A. A. et al. Aplicação de Quitosana Como Suporte Para a Imobilização de Enzimas de Interesse Industrial. Química Nova, v. 34, n. 5, p. 831-840, 2011.

RESENDE, M. A. Uso do Tanino Associado ao Sulfato de Alumínio Como Coagulantes Para o Tratamento de Efluente de Lavanderia Industrial. 2018. 60 f. Trabalho de Conclusão de Curso (Licenciatura em Química) - Universidade Federal de Uberlândia. Uberlândia, 2018.

ROSAlino, M. R. R. Potenciais Efeitos da Presença de Alumínio na Água de Consumo Humano. 2011. 85 f. Dissertação de Mestrado (Pós-Graduação em Engenharia do Ambiente, Perfil Sanitária) Faculdade de Ciências e Tecnologia, Universidade Nova de Lisboa, 2011.

SILVEIRA, B. A. Tratamento de Água de Abastecimento com Aplicação da Moringa oleífera Líquida e em pó em Diferentes Concentrações de Solução Salina. 2017. 61 f. Trabalho de Conclusão de Curso (Graduação em Engenharia Ambiental) - Universidade Tecnológica Federal do Paraná no Campus de Londrina. Londrina, 2017.

SPINELli, V. A. Quitosana, Polieletrólito Natural Para o Tratamento de Água Potável. 2001. 134 f. Dissertação de Mestrado (Pós-Graduação em Engenharia Ambiental), Universidade Federal de Santa Catarina, 2001.

VAZ, L. G. L. et al. Avaliação da Eficiência de Diferentes Agentes Coagulantes na Remoção de Cor e Turbidez em Efluentes de Galvanoplastia. Eclética Química, v. 35, n. 4, p. 45-54, 2010. 
